\title{
HOMOPHOBIC HARASSMENT WHERE NO ONE IS GAY
}

\author{
English v Thomas Sanderson [2008] EWCA 1421
}

Employment Equality (Sexual Orientation) Regulations 2003 SI 2003/1661

Mr English was harassed by colleagues using sexual innuendo suggesting he was homosexual. This conduct was rooted, apparently, in two things: he lived in Brighton (a well known centre of the gay scene) and had attended boarding school. What made this case unusual is that Mr English was heterosexual, and his tormentors neither assumed nor perceived Mr English to be gay. Mr English was aware throughout that his tormentors never mistook him for being homosexual. For these reasons the EAT found that the mockery did not amount to unlawful harassment on the grounds of sexual orientation. However, by a 2-1 majority, the Court of Appeal reversed.

The technical issue in this case was whether someone could be liable for harassment 'on the grounds of' sexual orientation, under regulation 5 of the Employment Equality (Sexual Orientation) Regulations 2003 SI 2003/1661, when the treatment was unrelated to any particular person's sexual orientation. The outcome is relevant to the many the statutory definitions employing the phrase on grounds of', such as harassment (and direct discrimination), on grounds of sex, religion or belief, race, age and disability, and gender reassignment.

There are two versions of the phrase, one narrow and one broad. Harassment is unlawful either 'on grounds of' a protected status (broad), or 'on grounds of' his protected status (narrow). It is, for example, the difference between 'on grounds of race', or 'on grounds of his race'. At present, the UK legislation provides a broad definition for race, sexual orientation, and religion or belief. The narrow definition covers gender reassignment and age. For sex, the harassment need only be related to her sex, an even broader phrase used to resolve a problem particular to gender (see EOC v Secretary of State for Trade and Industry [2007] ICR 1234 (HC Admin)). The Disability Discrimination Act 1995 carries the narrow definition, but this is unlikely to survive the ECJ's ruling that the parent 'Framework' Directive 2000/78/EC imposes the broad version (Coleman v Attridge Law Case C-303/06 [2008] IRLR 722 (ECJ)). Direct discrimination suffers from similar, albeit slightly varied, discrepancies.

The significance of the broad definition is that it extends the coverage to harassment or discrimination on the ground of a third party's protected status (e.g. harassing a white woman for marrying a black man), and to 'perceived' discrimination (e.g. harassing an Asian man on the mistaken belief that he is Muslim or a straight man on the mistaken belief he is gay).

The phrase 'on the ground of sexual orientation' lends itself to cover the scenario in the instant case. As Sedley LJ observed, the distance between perceived harassment and harassing a man as if he were gay when he is not 'is barely perceptible' ([38]). However, less technical considerations were prevalent in his reasoning ([39]):

[People] ... may desire to keep their orientation to themselves but still be vulnerable to harassment by people who know or sense what their orientation is. It cannot possibly have 
been the intention, when legislation was introduced to stop sexual harassment in the workplace, that such a claimant must declare his or her true sexual orientation in order to establish that the abuse was 'on grounds of sexual orientation'.... The case would have been exactly the same if Mr English had elected ... to remain silent about his actual sexual orientation.... And the same would be the case if he were actually gay or bisexual but preferred not to disclose it.

The underlying consideration here is to protect homosexual (or bisexual) workers from being 'outed' by a systematic campaign of abuse. In such a pernicious scenario, the worker would have to suffer the abuse in silence unless or until he 'came out'. As such, this decision helps preserve the dignity of workers that discrimination law is supposed to enshrine (see the text of regulation 5 and Coleman $v$ Attridge Law, ibid AG[8]-[15]).

In addition to harassment on protected grounds, sexual harassment is unlawful. The Sex Discrimination Act 1975, section 4A, prohibits 'conduct of a sexual nature that has the purpose or effect of violating her dignity or, of creating an intimidating, hostile, degrading, humiliating or offensive environment for her ...' Although this is provided by the Sex Discrimination Act, its scope is not limited to male-to-female conduct, or the reverse. The perpetrator is 'a person' while the victim is 'her' or 'him' (s 4A(5)). Thus 'same-sex' sexual harassment is covered by this provision and even before the English decision, victims of sexual harassment were under no obligation to reveal their sexual orientation. The abuse of Mr English included 'sexual innuendo' and 'lurid comments' ([3]), and so the abuse would appear to amount to sexual harassment as well as sexual orientation harassment. No mention of this apparent oversight was made in the judgment. Indeed, Sedley LJ (see the extract above) appeared to confuse sexual harassment with harassment on the ground of sexual orientation. That said, not all cases of homophobic abuse will be of a sexual nature, and so regulation 5 and this decision are not redundant.

The most obvious principle to emerge from this decision is that victims of sexual orientation harassment are under no obligation to disclose their sexual orientation to succeed. Thus, workers cannot be 'outed' by a campaign of harassment. Accordingly, victims of religious harassment should not be obliged to disclose their religion, and so on.

More broadly, the case draws attention to the numerous possibilities when defining harassment (or direct discrimination), which could be restricted to the claimant's protected status, or extended to cover perhaps, 'third-party' discrimination, perceived discrimination, and conduct unrelated to any particular person's condition. Various versions appear inconsistently and incoherently across the domestic legislation, and those definitions falling short of the broad possibility confirmed in English, fall short of the consistently broad definition provided by the predominant EC Directives.

Michael Connolly University of Surrey 